\title{
Characterization of sprawling in Kaduna metropolitan area
}

\author{
Ndabula, Christopher ${ }^{1}$, Jidauna, Godwill Geofrey ${ }^{1, ~ *}$, Averik, Peter Danjuma ${ }^{2}$, \\ Oyatayo, Taofik Kehinde ${ }^{3}$, Abaje, Iliya Bitrus ${ }^{1}$, Ali, Andesikuteb Yakubu ${ }^{3}$ \\ ${ }^{1}$ Department of Geography and Regional Planning, Faculty of Arts, Management, and Social Sciences, Federal University Dutsin-Ma, \\ Dutsinma LGA, Katsina State, Nigeria \\ ${ }^{2}$ Department of Geography and Environmental Management, University of Port-Harcourt, Rivers State, Nigeria \\ ${ }^{3}$ Department of Geography, College of Natural \& Applied science, Kwararafa University, Wukari, Taraba State, Nigeria
}

\section{Email address:}

jidauna@yahoo.com (Jidauna, G. G.)

\section{To cite this article:}

Ndabula, Christopher, Jidauna, Godwill Geofrey, Averik, Peter Danjuma, Oyatayo, Taofik Kehinde, Abaje, Iliya Bitrus, Ali, Andesikuteb Yakubu. Characterization of Sprawling in Kaduna Metropolitan Area. American Journal of Environmental Protection.

Vol. 3, No. 3, 2014, pp. 131-137. doi: 10.11648/j.ajep.20140303.14

\begin{abstract}
This study aims at using quantitative indices as an improved approach to characterize, analyze and explain urban sprawling beyond the traditional spatial or cartographic mapping and monitoring method which lacks the effectiveness to analyze and explain the details of temporal, horizontal and vertical dimensions of these urban sprawling. In this study, eight (8) indices; Built-up Change Intensity Index $\left(\mathrm{T}_{\mathrm{i}}\right)$, Built-up Dynamic Index $\left(\mathrm{K}_{\mathrm{i}}\right)$, Built-up Rate of growth $(\mathrm{L})$, Sprawling Index $\left(\mathrm{S}_{\mathrm{i}}\right)$, Net Urban Density Index $\left(\mathrm{D}_{1}\right)$, Marginal Density Index $\left(\mathrm{D}_{2}\right)$, and Fragmentation Index $\left(\mathrm{F}_{1}\right)$. These indices were based on three measures of urban growth parameters; measures based on land conversion, density trends and metropolitan form. These quantitative values computed were then interpreted infer if these urban growth patterns could be regarded as sprawling as well as to check for the rate and magnitude of sprawling and thus the environmental and socio-economic implications of these for the study area. RS/GIS methods facilitated achievement of results using cartographic modeling of urban spatial growth which provided estimates used for computation of indices under review. Results revealed that Built-up Change Intensity Index $\left(\mathrm{T}_{\mathrm{i}}\right)$ has a gradual increasing trend from $7.8 \%$ between 1967 and 1987 to $11.88 \%$ between 2001 and 2009. On the other hand both Built-up Dynamic Index $\left(\mathrm{K}_{\mathrm{i}}\right)$ and Rate of Growth (L) showed declining trend from 24.89 and $1.01 \%$ to 18.04 and $0.53 \%$ respectively between $1967 / 87$ and $2001 / 2009$. Deductions from all the indices used indicated that the growth patterns of Kaduna Metropolis cannot be significantly regarded as sprawling. Kaduna metropolis is a combination of traditional and modern city with compact built-up, even though it is surrounded with medium developments along its ribbon-like transportation routes including the Kaduna-Kachia, Kaduna-Abuja, to the south, Kaduna-Birnin Gwari and Kaduna-Zaria, to the north and along the Western-Bye pass and recently Eastern-Bye pass under construction.
\end{abstract}

Keywords: Sprawling, Metropolitan Growth, Sprawling Indices, Characterization, Cartographic Modeling

\section{Introduction}

Urban growth has played a major role in human civilization and has been the center of a wide variety of demographic, socio-economic and cultural responses, infrastructure and, leading to a complex interplay of institutional, technological, demographic, environmental factors which cause urban areas to be one of the most dynamic systems and the milieux of environmental, ecological, demographic and socio-economic problems [1, 2, 3, and 4].
The degree or level of urbanization is highest in the developed countries [5], whereas, the rate of urbanization is highest in the developing countries, about five (5) times faster than that of the developed countries [6]. Rapid urbanization is common to both developed and developing countries, but highest in the developing world especially in the last few decades. Urbanization is not new phenomenon in Africa, in fact, Africa is reported to have the highest growth rate [7]. In relation to Nigeria, the challenges posed by the rapid population growth have also been accompanied by rapid rates of unplanned urban expansion. 
This is responsible for millions of people living in sub standard and in some cases sub-human environment plagued by slums, filth and squalor and grossly inadequate social amenities [8]. Nigeria being the most populous country in Africa is undoubtedly suggested to have one of the most rapidly urbanizing cities.

Urban growth simply means land conversion from nonurban to urban, or expansion of urban area into adjacent/ neighborhood agricultural, forest, wetland and other nonurban lands [9]. Urban expansion in itself may not be a problem, but rather the nature and patterns of the urban growth. Urban sprawl also known as suburban sprawl is multifaceted and encompasses multiple aspects of urban growth pattern and can be characterized based on urban land use pattern and its associated impact on urban spatial structure (form/morphology), rate of land conversion and land use intensity. The concept of sprawling includes spreading outwards of a city and its suburbs to its outskirts, to low density, auto-dependent development on rural land, excessive, gluttonous, or ineffective urban space consumption in an uncontrolled and disorderly manner, leading to loss or poor distribution of open spaces, scattered development away from the central city and existing infrastructure, social separation and land use separation [9]. In developing countries of Latin America and Africa, urban sprawl is defined as a process of rapid expansion of the borders of cities through massive formation of peripheral settlements, which are in most cases large spontaneous, low income, squatter residential areas also referred to as slums [10]. Therefore, sprawling simply means rapid unplanned growth with extensive decentralization from the city center [10]. Major features of sprawling therefore, include rapid unplanned, discontinuous development, ineffective use of land, chaotic land use pattern, low density and low income residential (squatter) settlements with development away from city and existing infrastructure.

In recent times, rapid and unplanned urban growth or sprawling is strongly linked to urban environmental, ecological, socio-economic and demographic problems [11, and 12]. Understanding of urban growth processes and patterns has remained topical and fundamental in the approach to these socio-economic, demographic and environmental problems of urbanization. However, the need to characterize sprawling as it is associated with urban growth patterns is much more significant in the understanding of urban spatio-temporal dynamics and its related problems.

A complex inter-relationship can be observed between the indicators of urban sprawling such as land conversion, population density, land use intensity and urban morphology with socio-urban use. For instance, increasing population following demographic trends if accompanied with poor land management can result economic, demographic and environmental responses of the urban growth process such as ineffective land conversion, leaffrog or fragmented development. These processes can in turn cast a larger urban shadow on the landscape than necessary because of externalities from adverse land use such as clearing of vegetation cover, development on fragile ecosystems such as floodplain, swampy land, and steep slopes especially as the poor move to the urban fringes or marginal lands which are cheaper for development. The consequences of all processes may be diverse including high rate of destruction of ecological resources resulting in ecological, environmental degradation which in turn reinforce poverty and other socio-economic problems. The nature of urban growth arising from socio-economic/demographic processes can affect the urban growth form or structure which is also an important dimension of urban sprawling with probable effects on transportation behavior, infrastructural cost and many other socio-economic problems. Therefore, understanding the characteristics of urban sprawling can help explain processes that are behind urbanization, the resultant environmental and socio-economic problems, and thus decision making towards proffering solutions.

Characterization of urban sprawl is of immense significance considering the profound implications it has for economic efficiency, social equity and environmental sustainability of the urban environment [13]. Specific consequences of urban sprawl include higher cost of infrastructural provision [14], central city decline [15], poor transportation accessibility, increased road congestion associated with excessive suburban road construction and longer trips, lack of functional open spaces [16, and 10], environmental degradation [11], and loss of environmental resources [17].

There is great need to quantitatively analyze urban development patterns and to be able to characterize them using land use patterns and to enable a prediction of such patterns of sprawling. This can be very useful in explaining certain processes of urbanization and to be able to tackle specific socio-economic, demographic and environmental problems which are on the increase in urban centers. In Nigeria, most researchers have focused on monitoring of urban growth patterns or sprawling without bothering to really explain the characteristics of the sprawling beyond qualitative description and were they do, the only characterized sprawling judging on urban growth extents and rates majorly. For instance Olorunfemi [18] monitored urban growth in Ilorin, Oyinloye et'al [19] monitored growth of cities in Osun, south west of Nigeria, Balzerek [20] studied urban growth in Gombe, Kawka [21] monitored urban growth in Maiduguri and Ndabula [22] in Kaduna using GIS overlay analysis of built-up layers extracted from multi-temporal satellite datasets to cartographically study urban growth patterns, especially extents and rates. It is however inadequate to use only rate and extents of urban growth to conclude that there is sprawling, since not all urban growth patterns can be classified as sprawl.

To qualify urban growth pattern or forms as sprawling, rate of spatial growth must be coupled with spatial analysis based on some selected relevant quantitative or 
mathematical indices that combined elements of socioeconomic, demographic and environmental aspects of the urban growth problems. Spatial analysis study entities using their topological, geometric or geographic properties as a tool to visualize, analyze, model and interpret such geographic information to discover problem solving spatial relationships, trends and patterns.

It is at the background of this problem that this study is aimed at combining GIS cartographic modeling of urban spatial growth with spatial analysis based on selected quantitative indices that combine rate of urban growth, land use intensity and urban morphology using both LULC and demographic data, in order to characterize or established if there is sprawling in Kaduna metropolis. The parameters used in this study also provide information that is essential to assess and predict urban risk and environment in the future [23], while serving as decision support for urban planners and city government for both present and feature to mitigate for the problems of sprawling.

\subsection{Study Area}

Kaduna is located on the southern end of the high plains of Northern Nigeria, gridded by Latitude $10^{\circ} 40^{\circ} \mathrm{N}$ and $10^{\circ}$ $60^{\prime} \mathrm{N}$ and Longitude $7^{0} 10^{\prime} \mathrm{E}$ and $7^{0} 35^{\prime} \mathrm{E}$. The metropolis is historically founded on three firm bases legs; Administrative Capital, Industrial Town and as a Military Garrison. One principle of its master plan is the delineation of a 'functional territory' which was reclassified as 'inner zone' and an 'outer zone' to allow it function economically, socially and administratively as the capital within its natural city region and to control development within the local daily sphere of influence (Kaduna replanned,1990). The city was the second most industrialized city after Lagos in Nigeria in the 1970's, though this economic climate of Kaduna has got worse in the last two-three decades.

The city is located in a tropical continental climate with distinct wet and dry seasons. The bedrock geology is predominantly metamorphic rocks of the basement complex consisting of gneisses and older granites. The soils are typical red-brown to red-yellow tropical ferruginous soils with vegetation comprising savannah grassland with scattered trees and woody shrubs. The population of the city has experienced rapid growth from about 169125 in 1967 to a projected figure of 1371805 in 2009 from the 2006 population census.

\section{Methods and Data}

Remotely sensed satellite imageries including; LandSat MSS 1987, Spot.XS 1996, NigSat. 2006, and Quickbird, 2009 obtained from National Airspace Research and Development Agency at the nations' capital city Abuja. The choice of these images was based on availability. Erdas imagine 8.5 image processing software was used for classification of images, while ArcGIS software was used for the cartographic or spatial modeling of urban growth using over-lay analysis of vector layers of urban built-up layers extracted by digitization. The multi-temporal satellite data sets which transforms LULC by means of "Change detection" techniques executable on satellite data that are heterogeneous for spatial and spectral resolution with homogenization and registration in a unique digital information environment [4]. Kaduna urban growth map was composed and used in the measurement and monitoring and analysis of spatio-temporal dynamics of Kaduna urban spatial growth patterns. Land use/land cover change detection was carried out using Normalized Difference Vegetation Index (NDVI) analysis The NDVI helps mostly in the detection of vegetation change which is a proxy for sprawl intensity because if there is less vegetation it may mean more human occupation and more sprawl. note or add something like this for the NDVI calculations, see below.

The NDVI is a ratio of the near infrared and red spectral reflections and it is calculated as (NIR-VIS/NIR+VIS). Where VIS and NIR stand for the spectral reflectance measurements acquired in the visible red and near infrared regions of the electromagnetic spectrum respectively.

The simplifications of some previous studies which used rates of urban growth from this cartographic approach to infer sprawling falls below the conceptual and methodological framework of assessing sprawling, because it requires quantitative indices. The methodological approach in this study therefore, combined quantitative evaluation, measurement, analysis and spatial or cartographic modeling of urban spatial growth patterns using land use/land cover (LULC) and demographic data. The demographic, and land use/land cover (LUCC) data is based on the theoretical opinion that urbanization represents a response to specific demographic, socioeconomic or environmental factors. The quantitative indices of sprawling adopted combined measures based on land use and growth patterns such as; land conversion and density trends, population density and land use intensity and urban spatial structure or forms. These measures are the most basic and frequently used indicators of land use changes resulting from urban growth and sprawl [24]. For the purpose of this study, a total of eight $(8)$ indices: Builtup Change Intensity Index $\left(\mathrm{T}_{\mathrm{i}}\right)$, Built-up Dynamic Index $\left(\mathrm{K}_{\mathrm{i}}\right)$, Built-up Rate of growth (L), Sprawling Index $\left(\mathrm{S}_{\mathrm{i}}\right)$, Net Urban Density Index $\left(\mathrm{D}_{1}\right)$, Marginal Density Index $\left(D_{2}\right)$, and Fragmentation Index $\left(F_{1}\right)$. These indices were based on three measures of urban growth parameters; measures based on land conversion, density trends and metropolitan form.

Measures based on land conversion and land use structural changes:

(a) Built-up Rate of Growth (L)

$$
\mathrm{L}=10\left(\log \left(\mathrm{U}_{\mathrm{bi}}-\mathrm{U}_{\mathrm{ai}}\right)\right) / \mathrm{T}
$$

Where

$\mathrm{L}=$ Built-up Rate of Growth

$\mathrm{U}_{\mathrm{bi}}=$ Current Built-up Area 
$\mathrm{U}_{\mathrm{ai}}=$ Previous Built-up Area

$\mathrm{T}=$ period between current built-up and previous built-up

NB: this logarithmic approach according to (Landis, 2001)gives better estimates than the \% rate of growth.

(b) Built-up Change Intensity Index (Ti): the percentage that an area of built-up change is divided by total land area $\mathrm{B}$ in the study period. It can be used to compare the strength of land use change or potential trends (Wang, 2010)

$$
\mathrm{T}_{\mathrm{i}}=\left(\mathrm{U}_{\mathrm{bi}}-\mathrm{U}_{\mathrm{ai}}\right) / \mathrm{B}
$$

$\mathrm{T}_{\mathrm{i}}=$ intensity of the land use(built-up) change in the study period.

$\mathrm{U}_{\mathrm{ai}}=$ built-up area at the beginning.

$\mathrm{U}_{\mathrm{bi}}=$ built up area at the ending.

$\mathrm{B}=$ total area of study (Kaduna Inner Core Zone, which has been defined to include the city and its adjoining biophysical environment)

NB: This approach differs from built-up rate of growth, because it computes built-up as a land use in relation to other land uses, hence it uses built-up in comparison to total area.

(c) Built-up Dynamic Index: is the rate of change of built- up within a certain time (Wang, 2010)

$$
\begin{aligned}
& \mathrm{K}=\underline{-} \underline{\mathrm{U}_{\mathrm{i}}}-\mathrm{U}_{\mathrm{ai}} \times \underline{1} \times 100 \% \\
& \mathrm{U}_{\mathrm{ai}} \quad \mathrm{T}
\end{aligned}
$$

$\mathrm{K}=$ Built-up dynamic index for built-up within study period.

$\mathrm{U}_{\mathrm{ai}}=$ built up area at beginning.

$\mathrm{U}_{\mathrm{bi}}=$ built up area at ending.

$\mathrm{T}=$ study Period.

NB: This approach differs from rate of growth used in (a) above

Measures based on intensity of urban land use due to density trends [24]:

This is usually based on population density which quantifies the intensity of impact on urban land or biophysical environment.

(a) Net Urban Density Index $\left(D_{1}\right)$ : the most common index of urban growth and sprawl which expresses the relationship between population and built-up area.

$$
\text { Marginal Density }\left(D_{2}\right)=\frac{\text { Change in Urban Population }}{\text { Change in Urbanized land area }}
$$$$
\mathrm{D}_{1}=\mathrm{P}_{\mathrm{j}} / \mathrm{BA}_{\mathrm{j}}
$$

(c) Sprawling Index $\left(\mathrm{S}_{\mathrm{i}}\right)$

$$
\begin{gathered}
\mathrm{S}_{\mathrm{i}}=\frac{\text { Rate of Urban growth }}{\text { Rate of population growth }} \\
\mathrm{S}_{\mathrm{i}}=\frac{\mathrm{L}}{\mathrm{P}_{\mathrm{L}}}
\end{gathered}
$$

Where $\mathrm{Si}=$ Sprawling Index

$\mathrm{L}=$ Rate of urban growth
$\mathrm{P}_{\mathrm{L}}=$ Rate of population growth.

(1) Rate of urban growth (L)

$$
\mathrm{L}=10\left(\log \left(\mathrm{U}_{\mathrm{bi}}-\mathrm{U}_{\mathrm{ai}}\right)\right) / \text { Time }
$$

Where $\mathrm{L}=$ Urban growth rate

$\mathrm{U}_{\mathrm{ai}}=$ growth at beginning

$\mathrm{U}_{\mathrm{bi}}=$ growth at later period under consideration

$\mathrm{U}_{\mathrm{bi}}-\mathrm{U}_{\mathrm{ai}}=$ Increased in Urbanised area

$\mathrm{T}=$ period between observed growth.

(2) $P_{L}=$ Rate of population growth.

$$
\mathrm{P}_{\mathrm{L}}=10\left(\log \left(\mathrm{P}_{\mathrm{bi}}-\mathrm{P}_{\mathrm{ai}}\right)\right) \text { Time }
$$

Where $\mathrm{P}_{\mathrm{L}}=$ Population growth rate

$\mathrm{P}_{\mathrm{ai}}=$ population at beginning of year under consideration $\mathrm{P}_{\mathrm{bi}}=$ population at later year under consideration $\mathrm{P}_{\mathrm{bi}}-\mathrm{P}_{\mathrm{ai}}=$ Increase in population between observed period $\mathrm{T}=$ Period between two data under consideration.

Population projection: Using Exponential method

$$
\mathrm{P}_{\mathrm{t}}=\mathrm{Pe}^{\mathrm{rn}}
$$

Where $\mathrm{Pt}=$ Population at a future date

$\mathrm{p}=$ Population of the base year

$r=$ rate of growth $(3 \%=0.03)$

$\mathrm{n}=$ interval between then base year and the future year

NB 1963 and 1991 population censuses figures where used as base years to project for 1967, 1987 and 1995, 2001, 2009 respectively.

Measures based on urban spatial structures (metropolitan forms)

Spatial structure based sprawl indices are theoretically aimed at measuring spatial relationship. These include; The Gini coefficient, Moran and Geary coefficients, compactness index, continuity, fragmentation, proximity, density and centrality. In this study only the fragmentation and centrality indices will be considered.

$$
\text { Fragmentation Index }\left(F_{1}\right)=\frac{\text { Area of Urban patches }}{\text { No of Urban patches }}
$$

\section{Results}

Using the GIS-based cartographic modeling, the changes in urban growth was determined and used for quantitative analysis of sprawling indices based on land conversion, which include; Built-up land use Change Intensity Index $\left(\mathrm{T}_{\mathrm{i}}\right)$, Dynamic Index $(\mathrm{K})$, and Rate of Growth $(\mathrm{L})$ as shown in Table 1.

In Table 2, the spatial attributes of fragmented form subcenters of the Kaduna Metropolis were determined and used to compute Fragmentation Index $\left(\mathrm{F}_{1}\right)$ shown in Table 3. Similarly, both Rate of built-up growth (L) and Population growth $\left(\mathrm{P}_{\mathrm{L}}\right)$ were used to quantitatively express sprawling based on land use intensity parameters such as population density and urban form which include Net Population Density Index $\left(\mathrm{D}_{1}\right)$, Marginal Density Index 
$\left(\mathrm{D}_{2}\right)$, Sprawling Index $\left(\mathrm{S}_{\mathrm{i}}\right)$ as seen in Table 3.

Table 1. Summary Results and Analysis of Sprawling Indices based on Measures of Land Conversion( Land use Change Structure)

\begin{tabular}{|c|c|c|c|c|c|c|c|}
\hline 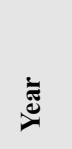 & 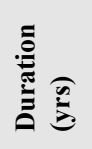 & 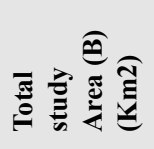 & 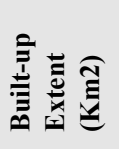 & 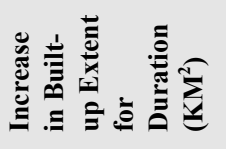 & 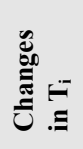 & 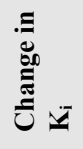 & 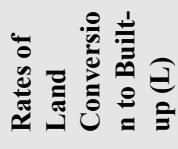 \\
\hline 1967 & - & 1346 & 21.10 & - & - & - & - \\
\hline 1987 & 20 & $"$ & 126.13 & 105.03 & 7.80 & 24.89 & 1.01 \\
\hline 1995 & 28 & , & 158.40 & 137.30 & 10.20 & 23.58 & 1.74 \\
\hline 2001 & 34 & $"$ & 172.47 & 151.37 & 11.25 & 21.10 & 1.64 \\
\hline 2009 & 42 & , & 181.91 & 159.91 & 11.88 & 18.04 & 1.53 \\
\hline
\end{tabular}

Table 2. Statistics of Sub-Centers Spatial Attributes.

\begin{tabular}{|c|c|c|c|c|c|c|}
\hline S/No & Name of Sub-Centers & Length (KM) & Breadth (KM) & Distance from CBD $\left(d_{c b d}\right)(K M)$ & Perimeter (KM) & Area $\left(K^{2} M^{2}\right)$ \\
\hline 1 & Gonin-gora & 3.72 & 1.94 & 10.84 & 14.09 & 4.54 \\
\hline 2 & Ung Romi & 2.50 & 1.92 & 9.90 & 8.15 & 2.21 \\
\hline 3 & Mahuta & 1.53 & 1.11 & 11.23 & 5.59 & 0.90 \\
\hline 4 & NNPC & 1.80 & 0.99 & 10.35 & 4.92 & 1.43 \\
\hline 5 & Ung Television & 3.64 & 2.10 & 8.58 & 10.14 & 4.32 \\
\hline 6 & Sabon Tasha & 3.96 & 2.45 & 9.03 & 12.36 & 4.32 \\
\hline 7 & Ung Sunday & 1.66 & 0.78 & 7.80 & 4.75 & 1.15 \\
\hline 8 & Mahuta Ext. & 0.87 & 0.52 & 9.67 & 2.87 & 0.26 \\
\hline 9 & Ung. Borou & 2.61 & 1.42 & 8.69 & 7.76 & 2.13 \\
\hline 10 & Ung. Pama & 1.64 & 0.76 & 7.50 & 4.38 & 0.98 \\
\hline 11 & Narayi High Cost & 2.24 & 1.52 & 6.64 & 8.90 & 2.49 \\
\hline 12 & Nasarawa & 3.74 & 1.36 & 6.71 & 9.85 & 2.93 \\
\hline 13 & Kudenda & 5.83 & 2.09 & 7.73 & 15.27 & 5.66 \\
\hline 14 & Narayi & 2.52 & 1.92 & 5.45 & 8.33 & 0.23 \\
\hline 15 & Barnawa & 5.40 & 2.09 & 5.23 & 14.28 & 9.04 \\
\hline 16 & Kakuri & 7.12 & 2.59 & 7.18 & 19.56 & 13.55 \\
\hline 17 & Ung Muazu & 3.09 & 1.48 & 4.97 & 4.89 & 1.02 \\
\hline 18 & Kabala Doki & 2.36 & 1.78 & 2.70 & 7.40 & 2.13 \\
\hline 19 & Ung. Muazu Ext, & 1.77 & 0.86 & 6.59 & 7.75 & 3.28 \\
\hline 20 & Kamanzo & 0.51 & 0.30 & 4.90 & 1.35 & 0.11 \\
\hline 21 & Janruwa Ext. & 0.21 & 0.06 & 5.57 & 0.51 & 0.01 \\
\hline 22 & Janruwa & 0.61 & 0.23 & 6.39 & 2.87 & 0.09 \\
\hline 23 & T/Wada\&Nupawa & 7.34 & 3.00 & 2.45 & 20.59 & 12.22 \\
\hline 24 & Ung. Rimi & 4.65 & 2.73 & 3.30 & 13.17 & 5.74 \\
\hline 25 & Doka & 5.94 & 3.59 & 0 & 18.26 & 12.51 \\
\hline 26 & Badiko West & 1.27 & 1.28 & 4.00 & 4.61 & 0.81 \\
\hline 27 & Badiko East & 3.49 & 1.05 & 2.89 & 9.62 & 3.08 \\
\hline 28 & Rigasa & 5.38 & 3,64 & 5.67 & 16.84 & 13.01 \\
\hline 29 & K/Mashi & 1.67 & 1.30 & 3.87 & 5.90 & 1.62 \\
\hline 30 & Abakpa/Kanawa & 3.12 & 0.36 & 3.12 & 8.88 & 1.81 \\
\hline 31 & Farin-gida Ext. & 0.07 & 0.03 & 5.40 & 0.18 & 0.02 \\
\hline 32 & Farin-gida & 0.47 & 0.17 & 5.80 & 1.75 & 0.06 \\
\hline 33 & Malali & 5.71 & 2.64 & 4.42 & 18.16 & 11.45 \\
\hline 34 & Badarawa/Dosa & 3.03 & 2.38 & 5.55 & 10.55 & 5.12 \\
\hline 35 & NDA/Kotoko & 3.76 & 2.88 & 4.78 & 11.92 & 8.00 \\
\hline 36 & Hayin-Banki & 1.85 & 1.66 & 6.70 & 6.13 & 1.77 \\
\hline 37 & Hayin Rafin-guza & 3.32 & 1.36 & 7.33 & 10.39 & 35.31 \\
\hline 38 & Ung. Gwari & 2.65 & 1.74 & 8.40 & 8.35 & 3.07 \\
\hline 39 & Mando & 5.13 & 2.90 & 7.38 & 29.87 & 12.60 \\
\hline 40 & Trade fair & 1.15 & 0.40 & 10.27 & 3.00 & 0.42 \\
\hline 41 & Airforce Village & 0.80 & 0.55 & 9.69 & 2.53 & 0.29 \\
\hline 42 & NDA (New-site) & 3.10 & 2.21 & 11.73 & 9.04 & 4,21 \\
\hline 43 & Riga chikun Ext. & 1.39 & 0.56 & 11.55 & 3.64 & 0.48 \\
\hline 44 & Riga chikun & 2.08 & 0.89 & 8.29 & 29.87 & 0.13 \\
\hline 45 & Airforce-base & 2.71 & 1.05 & 309.80 & 419.89 & 180.47 \\
\hline
\end{tabular}


Table 3. Summary and Analysis of Sprawling Indices based on Urban Land use Intensity (Population density and Urban Form)

\begin{tabular}{|c|c|c|c|c|c|c|c|c|c|c|}
\hline 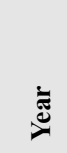 & 童 & 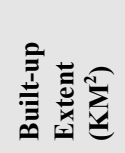 & 先 & 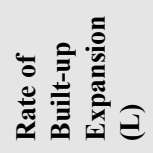 & ڤే & 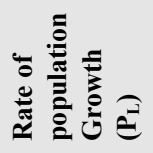 & 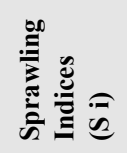 & 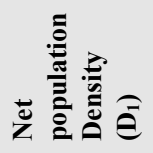 & 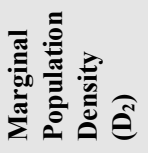 & 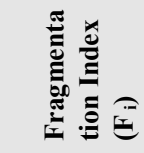 \\
\hline 1967 & - & 21.10 & - & - & 169125 & - & - & 8,015 & - & 1.06 \\
\hline 1987 & 20 & 126.13 & 105.03 & 1.01 & 308166 & 2.57 & 0.39 & 2,443 & 1,324 & 3.94 \\
\hline 1995 & 28 & 158.40 & 137.30 & 1.74 & 902000 & 7.22 & 0.26 & 5,674 & 18,088 & 4.28 \\
\hline 2001 & 34 & 172.47 & 151.37 & 1.64 & 1079889 & 8.75 & 0.22 & 6,261 & 13,167 & 4.31 \\
\hline 2009 & 42 & 181.01 & 159.91 & 1.53 & 1371805 & 6.88 & 0.17 & 7,584 & 34,299 & 4.02 \\
\hline
\end{tabular}

\section{Discussions}

The results of cartographic modeling of urban growth showed that built-up area has experience increasing expansion from about $21.10 \mathrm{~km}^{2}$ in 1967 to $126.13 \mathrm{~km}^{2}$ to $172.47 \mathrm{~km}^{2}$ and $181.01 \mathrm{~km}^{2}$ in 1987,2001 and 2009 respectively. Similarly, indices of Built-up Land use Change Intensity Index $\left(\mathrm{T}_{\mathrm{i}}\right)$ has shown a gradual increasing trend from 7.8 to $11.88 \%$, while Dynamic Index $(\mathrm{K})$ has been declining from 24.89 to $18.04 \%$ and Rate of growth (L) from 1.01 to $0.53 \%$ from 1967 to 2009 respectively. The results also revealed that temporal patterns indicated highest rates of growth and dynamic changes between 1967 and 1987, which corresponded with the period of rapid industrialization which ranked Kaduna second most industrialized state after Lagos in Nigeria. It could be reasoned that the economic recession from the late 80 s to date have been responsible for slower rates of growth. Other factors may include the recurrent ethno-religious crisis that rocked the metropolis within these years coupled with the pull effect the Federal Capital (Abuja) exerts on adjourning cities including Kaduna.

The quantified indices of sprawling showed low and declining rate of conversion of rural or agricultural lands to built-up which is the most visible impact of urban growth. The population related indices indicated higher values of both $\mathrm{D}_{1}$ and $\mathrm{D}_{2}$ suggesting that less land resources is consumed by urban development, meaning that there is no gluttonous use of land space since land is rather intensively used, especially in new urban developing areas. This is further indicated the greater values of $D_{2}$ over $D_{1}$ which refer to higher population densities as against the lower population densities that usually characterize sprawling. This also implies that environmental or ecological impact due to urban expansion is less. The observed lower values of sprawling index of less than $1(<1)$ which is a useful benchmark indicates that land has been used more intensively in new urbanizing areas. Fragmentation index has not significantly changed over time as it merely progressed from 1.06 to 4.02 from 1967 to 2009 and hence lower costs of infrastructural provision, relatively shorter trips and lesser transportation cost and facilitates pedestrian activities and public transportation, routine administration and security more cost effective. In a nut shell it can be deduced that Kaduna metropolis though has been growing, but the patterns cannot be significantly regarded as sprawling. Kaduna metropolis is a combination of traditional and modern city with compact built-up, even though it is surrounded with medium developments along its ribbon-like transportation routes including the KadunaKachia, Kaduna-Abuja, to the south, Kaduna-Birnin Gwari and Kaduna-Zaria, to the north and along the Western-Bye pass and recently Eastern-Bye pass under construction.

\section{Conclusions}

From the results and discussions it can be concluded that the growth patterns of Kaduna metropolis are gradually revealing evidences of sprawling but not on serious rate. The low fragmentation index represents low level of leapfrog development or less of gluttonous consumption of land.

\section{References}

[1] Yang, X., and LO,C.P., (2003) Modeling Urban Growth and Landscape Changes in the Atlanta Metropolitan Area. International Journal of Geographical Formation Systems, Vol. 17(5):463- 488.

[2] Masek, T.G., Luidsay, F.E., and Goward, S.N., (2000) Dynamics of Urban Growth in the Washington DC. Journal Metropolitan Area, 1973 - 1996, for Land Sat Observation, International Journal of Remote Sensing Vo. 21. Issue 18 December 2008, Pp 3473-3486. http:// www. informatould.com/smpp/ content.

[3] Jidauna, G.G., Dabi, D.D. and Dia, R. (2011). The Effect of Climate Change on Agriculture in Selected Settlements of Sudano-Sahelian Region of Nigeria, Scholars Research Library, Archives of Applied Science Research, Volume 3, Number 6, Pages. 154-165. http://scholarsresearchlibrary.com/archive.html

[4] Ndabula, C., Jidauna, G.G., Oyatayo, K., Averik, P.D., and Iguisi, E.O., (2012). Analysis of Urban Floodplain Encroachment: Strategic Approach to Flood and Floodplain Management in Kaduna Metropolis. Journal of Geography and Geology, Vol.4, No.1, Pages. 170-182. www.ccsenet.org/jgg

[5] Anthrop, M.,(2004) Landscape Change and the Urbanization Processes in Europe. Landscape and Urban Planning, 67(1-4), pp 9-26.

[6] Lopez, E., Bocco, G., Mendozoa, M., and Duhau, E.,(2001) Predicting Land cover/Land use Change in the Urban Fringe. A case in Morelia City, Mexico. Landscape and Urban Planning, 55, pp 271-285. 
[7] World Resources Institute, (1997). World Resources 199697: The Urban Environment, Washington DC., WRI.

[8] Bankole, M.O., Bakare, H.O., and Oderinde, F.O., (2011). Changing Trend of surface To Built-up Environment and its Effects on Urban Climate of Ibadan, Nigeria.

[9] Hasse J.E., and Lathrop, R. G., (2003) Land Resources Impact indicator of Urban Sprawl. Applied Geography 23: 159-175.

[10] Shen, Q., Liao, J.,and Zhang, F., (2003) Changing Urban Growth Patterns in a Pro-Smart Growth State: The Case of Mary land,1973-2000. Growth_121305.pdf.http://www.smartgrowth.umd.edu/resea $\mathrm{rch} / \mathrm{pdf} /$ ShenLiaoZhang_ChangingUrban

[11] Daniels, T.,and Daniels, K., (2003) Environmental Planning APA Planners Press

[12] Dabi, D. D \& Jidauna, G.G (2010). Climate change and local perception in selected settlement in the Sudano-Sahelian region of Nigeria. Journal of Environmental Sciences and Resources Management. Volume 2, Pages. 1-12. http://www.cenresinpub.org/jesrmdec10.html

[13] Downs, A., (1998) How American Cities are Growing: The Big Picture. Brookings Review 16(4):8-11.

[14] Butchell, R.W., George, L., Dolphin. C.G., Downs, A., Siskin, S., Still, K.G., and Moore, T., (2002) Cost of Sprawls. TRCP Report 74 Washington DC: Natural; Academy Press.

[15] Downs, A., (1999) Some Realities about Sprawl and Urban Decline. Housing Policy Debate 10:955-974.

[16] Ewing, R., (1997) Is Los Angeles Style Sprawl Desirable? Journal of the American Planning Association 63(1):107126.
[17] Nelson, A.C., (1992) Preserving Prime Farmland in the Face of Urbanization: Lesson from Oregon . Journal oft the American Planning Association 58(4): 467-488.

[18] Olorunfemi, J.F., (1987) Identification and Measurement of the Areal Extent of Settlement from Landsat: An Exploration into the Nigerian Case. International Journal of Remote Sensing (8) 12: 1839 - 1843.

[19] Oyinloye, R.O., Abgo, B.F., and Aliyu, Z.O., (2002) Application of Nigerian Sat 1 Data for Land use/Land cover Change Mapping. National Space Research and Development Agency NASRDA News Vol. 7, Issue , 3Pp 2024.

[20] Balzerek, H., (2001) Application of Ikonos Satellite Scores in Monitoring Classification and Evaluation of Urbanization process in Gombe, Nigeria. Regeusbuger Geographic Schriften Vol. 34. P50.70.

[21] Kawka, R., (1996) African Urban Land Classification Using Satellite Imaging. Example of Maiduguri NF, Nigeria. Paper presented at the $39^{\text {th }}$ Annual Conference of Nigerian Geographical Association, Maiduguri, 1996. P.23-27.

[22] Ndabula C., (2005) Assessment of Land use/ Land cover changes in Kaduna Metropolitan Area. Unpublished M,Sc Thesis, Department of Geography, ABU Zaria

[23] Shigenobu, T., Tran Shiro, O.. Yoshifumi, Y., (2003) Monitoring of Long-term Urban Expansion by the Use of Remote Sensing Images for Different Sensors, in Bangkok Metropolitan Persia. Japan Remote Sensing Journal, 17 (1) Pg 54-64.

[24] Landis, J.D., (2001) Urban sprawling in California. Unpublished Project Report on Urban Sprawling in California, Department of City and Regional Planning, University of California, Berkeley. 